\section{EULAR recommendations for disease management: guidance not guidelines}

\author{
David S Pisetsky
}

The past two decades have witnessed remarkable advances in the treatment of inflammatory arthritis that have made remission in previously untreatable conditions a realistic goal for many patients. These advances derive from new insights into disease mechanisms; the advent of the biologics and other new therapies; the development of robust measures of disease activity; coherent treatment strategies to guide therapy (ie, treat to target or T2T); and a sufficient supply of rheumatologists to implement the new approaches. ${ }^{1}$

The advances in rheumatology have been unprecedented and, arguably, the treatment of inflammatory arthritis has progressed faster and further than that of any other serious chronic disease in all of medicine. Indeed, a patient with rheumatoid arthritis (RA) today can lead an essentially normal life, whereas, a few decades ago, such a patient would have a restricted existence and be easily recognised by the appearance of grave illness, wasting and deformity.

Along with better outcomes have come challenges in the utilisation of the current armamentarium of disease modifying antirheumatic drugs or DMARDs (table 1). These challenges are, of course, welcome since they signify progress. In the face of literally hundreds to thousands of ways to treat arthritis and the continuing influx of novel agents, they also demand guidance for both providers and patients to establish a treatment plan, recognising potential risks, benefits and costs. The publication of three articles on European League Against Rheumatism (EULAR) recommendations for the treatment of early inflammatory arthritis, RA and axial spondyloarthritis (axSpA) is therefore an important event and provides a much needed perspective and framework for the delivery of best care. ${ }^{2-4}$

Each article represents a remarkable effort by panels of rheumatologists, health

Department of Medicine, Duke University Medical Center, Durham VAMC, Durham, North Carolina 27705, USA

Correspondence to Dr David S Pisetsky, Department of Medicine, Medical Research Service, 151G, Durham VAMC, Durham, NC 27705, USA;

david.pisetsky@duke.edu professionals and patient representatives to encompass an ever-expanding literature and provide overarching principles as well as specific recommendations. The work of the panels followed guidelines established by $\operatorname{EULAR}^{5}$ and involved systematic literature reviews (SLRs) which are published separately. ${ }^{6-12}$ The methodology is state of the art and meticulous, reflecting expertise of skilled methodologists and exceptional work of fellows and medical librarians to construct the SLRs. As described in the articles, deliberations of panel members were fair and democratic, with balloting on recommendations conducted until there was agreement.

The discussions in these articles are detailed and thoughtful as the authors explain their reasoning and choice of words. 'Wordsmithing' is sometimes denigrated as a seemingly pedantic exercise. Wordsmithing, however, is a serious undertaking to clarify thinking and enhance communication. Thus, in the RA recommendations, the wording on the approach to therapy when the first attempt does not reach the treatment target has been revised from 'change to another csDMARD strategy should be considered' to 'other csDMARDs should be considered.' This difference is important and many examples of such word choices illustrate the care devoted to their selection. Among these is the use of the word recommendation rather than guideline.

Of the recommendations, those on the management of early arthritis and RA address a central element of rheumatology. Given the size of the published literature, the data underpinning the recommendations are extensive and provide a solid evidence base. In many respects, the recommendations are consistent with the current practice in which T2T approaches are widely followed. ${ }^{13}$ These recommendations contain few surprises or controversial elements. Perhaps the major changes relate to the position of triple therapy in the hierarchy of therapy and the role of glucocorticoids.

As is the case of many treatment strategies for RA, the role of glucocorticoids remains uncertain despite almost 70 years of their use. Unquestionably, glucocorticoids are potent anti-inflammatory agents. For a person with active disease, symptom relief is essential and glucocorticoids can achieve that goal for many patients. Such symptom relief can improve quality of life almost immediately, give hope and solidify a relationship with a rheumatologist. Furthermore, a period of glucocorticoids can provide an umbrella until the onset of action of a DMARD.

The recommendations on RA management state that 'Short-term glucocorticoids should be considered when initiating or changing csDMARDs...but should be tapered as rapidly as clinically feasible.' Such an approach can spare the long-term toxicity of high-dose glucocorticoids but the rapidity of tapering and clinical feasibility are often unclear. Review of clinical trials indicates that a significant number of patients with chronic RA remain on low-dose glucocorticoids (5-7.5 mg prednisone or equivalent), suggesting that short term can be months to years and clinical feasibility may not readily occur. Glucocorticoids may provide bridge therapy and can be included in therapy in a number of different dose protocols, including daily oral administration as well as intravenous pulses, but, in the real world, the bridge can be very long especially as these agents have benefits on radiographs. ${ }^{14-20}$

Another issue relates to the recommendation that 'Treatment should be aimed at reaching a target of sustained remission or low disease activity.' While composite measures (eg, Disease Activity Score 28 (DAS28), Clinical Disease Activity Index and Simple Disease Activity Index) are valuable, the difference between a state of low disease activity and moderate disease activity can be as small as one or two tender joints, a small elevation in the C-reactive protein (CRP) value or a heightened patient global assessment

Table 1 Disease-modifying antirheumatic drugs (DMARDs)

\begin{tabular}{ll}
\hline Class & Example \\
\hline Conventional synthetic DMARD & Methotrexate, lefunomide \\
Targeted synthetic DMARD & Tofacitinib \\
Biological DMARD & \\
$\quad$ Biological originator & Infliximab \\
$\quad$ Biosimilar & Infliximab-dyyb \\
\hline
\end{tabular}




\section{Patient with Chronic Low Back Pain}
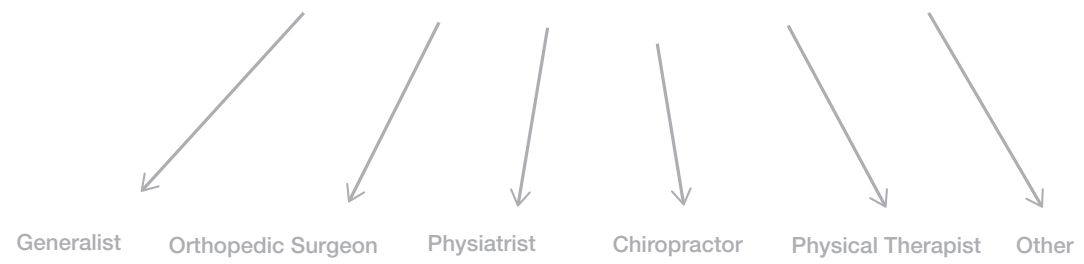

Generalist

Orthopedic Surgeon

Physiatrist

Chiropractor

Screening questionnaire for inflammatory back disease

HLA B27

Imaging

low back pain may have unrecognised axSpA. ${ }^{29-32}$ Thus, the recommendations for management of axSpA are relevant only for patients who have a diagnosis but it is very likely that many patients with axSpA never get a diagnosis.

Treatment of RA and axSpA also differs in the impact of biological therapy on radiographic outcome. While the effects of DMARDs on erosions are clear, studies have not definitely shown that agents such as tumour necrosis factor (TNF) blockers can change the development of syndesmophytes likely because the process is slow. Interestingly, non-steroidal anti-inflammatory drugs may affect radiographic progression. ${ }^{33-38}$ In the absence of radiographic evidence of disease modification, the evaluation of efficacy of therapy is based substantially on patient-reported outcomes of pain, stiffness and function. This situation may have contributed to the decision of the Food and Drug Administration to withhold approval for the use of TNF blockers for nr-axSpA.

Cost is now an important consider-

on a 'bad day.' For a patient, a decrease in the DAS28 from 6 to 4 can represent extraordinary improvement and, even if the disease activity rates as moderate, there can be reluctance to switch therapy especially as the benefits of any new agent are unknown and flare is possible. Such concerns can represent an important patient factor in recommendations on T2T. ${ }^{21}$ Furthermore, in the 2016 recommendations, patient factors are considered in the context of the Overarching Principle $\mathrm{B}$, with further discussion in the text related to Recommendation $2 .{ }^{4}$

In contrast to the arthritis recommendations, those for axSpA raise more weighty questions reflecting the differences in these conditions. The management of RA derives from a well-established narrative in which inflammation leads to joint destruction, deformity and impaired quality of life. Biomarkers (ie, anticyclic citrullinated peptide and rheumatoid factor) aid in patient diagnosis while imaging can show damage by erosions on plain X-rays. The situation with axSpA is different since diagnosis can be tricky; radiographic findings may be scant; and diagnostic biomarkers, beyond HLA B-27, are generally lacking. ${ }^{22-25}$

In the face of these conundrums, the recommendations on axSpA (a combined effort of EULAR and the Assessment of SpondyloArthritis international Society) are therefore timely. A central challenge in formulating recommendations for axSpA relates to disease definition. In the past, a diagnosis of ankylosing spondylitis was based on the presence of sacroiliitis (SI) by plain X-rays in a patient with inflammatory back pain. Inflammatory back pain entails insidious onset, worsening in the morning, improvement with activity and a lack of improvement with rest. The difficulty with this construct relates to inherent problems with SI joint radiography and, indeed, the absence of any X-ray evidence of SI disease in some patients with inflammatory back disease. ${ }^{26}$

The more recent conceptualisation of axSpA disease takes a different direction and posits that axSpA can be either radiographic or non-radiographic. ${ }^{27} 28$ Those with findings of SI can be termed ankylosing spondylitis; those without such findings are termed non-radiographic axSpA or nr-axSpA. Patients with nr-axSpA may have MRI findings but such imaging is expensive and often not available; levels of inflammatory markers such as CRP are often not elevated. As a result, the diagnosis of nr-axSpA can be uncertain unless there is a 'classic' inflammatory back pain and other findings (eg, psoriasis, uveitis) that support the diagnosis by an experienced rheumatologist.

An important issue in managing patients with axSpA concerns their care before diagnosis. Patients with inflammatory back pain can see orthopaedists, physiatrists, chiropractors and physical therapists among others and years may pass before the diagnosis of axSpA is made or even considered. As shown in studies on screening strategies to identify patients with axSpA, many patients with chronic ation in the formulation of treatment recommendations. ${ }^{39}$ The treatment of RA involves both new and old agents. The older agents (ie, conventional synthetic DMARDs like methotrexate) are not costly and can produce results comparable to those of the newer, more expensive agents, either targeted synthetic DMARDs or biological DMARDs. Since the older agents can be combined and used in conjunction with low-dose prednisone, a satisfactory treatment programme can be developed at a low cost. ${ }^{40}$

For axSpA, the situation is different. As the recommendations state, in describing the agents for axSpA, 'Some of them are very cheap; others are very expensive; there is little middle ground. Thus, as stated in the recommendations, 'For the first time, cost considerations received a prominent place in the axSpA recommendations.' Given the lack of more strong evidence for the effects of treatment on radiographic progression, the cost-benefit calculation for the new agents will be a subject of inquiry and, likely, debate. Furthermore, the introduction of biosimilars should yield cost savings in the administration of biological agents for axSpA as well as RA; the extent of these savings will likely vary by country and the magnitude of cost reduction. As long as the safety and efficacy of the biosimilars are comparable to the reference products, the cost savings can allow more widespread treatment with biological agents and a decrease in health disparities related to economic differences among countries. ${ }^{41} 42$ 
The authors of these three sets of recommendations have performed a valuable service for the field, facilitating best practice, providing guidance that is actionable and highlighting areas for future research. Thus, as inferred in the recommendations on axSpA, the rheumatologist should be facile in using measures such as Ankylosing Spondylitis Disease Activity Score and Bath Ankylosing Spondylitis Activity Index and the nuances of treating a disease where patient-reported outcomes predominate. ${ }^{43}$ Training, especially at the fellowship level, may be necessary to gain those skills. Furthermore, rheumatologists must develop an interdisciplinary approach to collaborate with other providers to identify among the large population of patients with low back pain, the minority of patients who have an axSpA. The logistical challenges for such an undertaking are large but, to improve the care of patients with axSpA, correct diagnosis is essential. Figure 1 illustrates the flow of patients to the rheumatologist and the importance of screening strategies.

Each article concludes with a research agenda, addressing such issues as induction strategies, remission and drug tapering. Such agendas are only likely to increase as new products achieve regulatory approval. Despite their importance, many of the proposed research questions will never be fully answered as the field constantly shifts and expands. The list of research questions, however, is a sign of vitality and dynamism in rheumatology and it was not so long ago that a central issue in the field concerned whether impacting the course of serious inflammatory arthritis was at all possible. Clearly, much is now possible and the research agendas exemplify the achievements of today as well as the hopes for tomorrow.

\section{Competing interests None declared.}

Provenance and peer review Commissioned; externally peer reviewed.

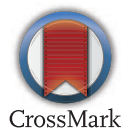

To cite Pisetsky DS. Ann Rheum Dis 2017;76:935-938.

\section{CLinked}

- http://dx.doi.org/10.1136/annrheumdis-2016210602

- http://dx.doi.org/10.1136/annrheumdis-2016210770

- http://dx.doi.org/10.1136/annrheumdis-2016210708
- http://dx.doi.org/10.1136/annrheumdis-2016210711

http://dx.doi.org/10.1136/annrheumdis-2016210713

- http://dx.doi.org/10.1136/annrheumdis-2016210715

Ann Rheum Dis 2017;76:935-938.

doi:10.1136/annrheumdis-2016-211005

(C) Article author(s) (or their employer(s) unless otherwise stated in the text of the article) 2017. All rights reserved. No commercial use is permitted unless otherwise expressly granted.

\section{REFERENCES}

1 Smolen JS, Aletaha D. Rheumatoid arthritis therapy reappraisal: strategies, opportunities and challenges. Nat Rev Rheumatol 2015;11:276-89.

2 Combe B, Landewe R, Daien $\mathrm{Cl}$, et al. 2016 update of the EULAR recommendations for the management of early arthritis. Ann Rheum Dis 2016;75:44-5.

3 van der Heijde $D$, Ramiro $S$, Landewé $R$, et al. 2016 update of the ASAS-EULAR management recommendations for axial spondyloarthritis. Ann Rheum Dis 2017;76:978-91.

4 Smolen JSL, Bijlsma R, Burmester H, et al. EULAR recommendations for the management of rheumatoid arthritis with synthetic and biological disease-modifying antirheumatic drugs. Ann Rheum Dis 2017:76:960-77.

5 van der Heijde D, Aletaha D, Carmona L, et al. 2014 update of the EULAR standardised operating procedures for EULAR-endorsed recommendations. Ann Rheum Dis 20152015;74:8-13;74:8-13.

6 Daien $\mathrm{Cl}$, Hua C, Combe B, et al. Nonpharmacological and pharmacological interventions in patients with early arthritis: a systematic literature review informing the 2016 update of EULAR recommendations for the management of early arthritis. RMD Open 2017;3:e000404

7 Hua C, Daien Cl, Combe B, et al. Diagnosis, prognosis and classification of early arthritis: results of a systematic review informing the 2016 update of the EULAR recommendations for the management of early arthritis. RMD Open 2017;3:e000406.

8 Regel A, Sepriano A, Baraliakos X, et al. Efficacy and safety of non-pharmacological and non-biological pharmacological treatment: a systematic literature review informing the 2016 update of the ASAS/ EULAR recommendations for the management of axial spondyloarthritis. RMD Open 2017;3:e000397.

9 Sepriano A, Regel A, van der Heijde D, et al. Efficacy and safety of biological and targeted-synthetic DMARDs: a systematic literature review informing the 2016 update of the ASAS/EULAR recommendations for the management of axial spondyloarthritis. RMD Open 2017:3:e000396

10 Nam JL, Takase-Minegishi K, Ramiro S, et al. Efficacy of biological disease-modifying antirheumatic drugs: a systematic literature review informing the 2016 update of the EULAR recommendations for the management of rheumatoid arthritis. Ann Rheum Dis 2017;76:1108-13.

11 Chatzidionysiou KES, Nam J, et al. Efficacy of glucocorticoids, conventional and targeted synthetic disease-modifying antirheumatic drugs: a systematic literature review informing the 2016 update of the EULAR recommendations for the management of rheumatoid arthritis. Ann Rheum Dis 2017:76:1102-7.

12 Ramiro SSA, Chatzidionysiou K, et al. Safety of synthetic and biological DMARDs-a systematic literature review informing the 2016 update of the EULAR recommendations for management of rheumatoid arthritis. Ann Rheum Dis 2017;76:1093-101.
13 Smolen JS, Breedveld FC, Burmester GR, et al. Treating rheumatoid arthritis to target: 2014 update of the recommendations of an international task force. Ann Rheum Dis 2016;75:3-15.

14 van Everdingen AA, Siewertsz van Reesema DR, Jacobs JW, et al. The clinical effect of glucocorticoids in patients with rheumatoid arthritis may be masked by decreased use of additional therapies. Arthritis Rheum 2004;51:233-8.

15 Goekoop-Ruiterman YP, de Vries-Bouwstra JK, Allaart $C F$, et al. Clinical and radiographic outcomes of four different treatment strategies in patients with early rheumatoid arthritis (the BeSt study): a randomized, controlled trial. Arthritis Rheum 2005;52:3381-90.

16 Durez P, Malghem J, Nzeusseu Toukap A, et al. Treatment of early rheumatoid arthritis: a randomized magnetic resonance imaging study comparing the effects of methotrexate alone, methotrexate in combination with infliximab, and methotrexate in combination with intravenous pulse methylprednisolone. Arthritis Rheum 2007:56:3919-27.

17 Bakker MF, Jacobs JW, Welsing PM, et al; Utrecht Rheumatoid Arthritis Cohort Study Group. Low-dose prednisone inclusion in a methotrexate-based, tight control strategy for early rheumatoid arthritis: a randomized trial. Ann Intern Med 2012;156:329-39.

18 de Jong PH, Hazes JM, Han HK, et al. Randomised comparison of initial triple DMARD therapy with methotrexate monotherapy in combination with low-dose glucocorticoid bridging therapy; 1-year data of the tREACH trial. Ann Rheum Dis 2014;73:1331-9.

19 Nam JL, Villeneuve E, Hensor EM, et al. Remission induction comparing infliximab and high-dose intravenous steroid, followed by treat-to-target: a double-blind, randomised, controlled trial in newonset, treatment-naive, rheumatoid arthritis (the IDEA study). Ann Rheum Dis 2014;73:75-85.

20 Boers M, Aletaha D, Mela CM, et al. Glucocorticoid effect on radiographic progression in placebo arms of rheumatoid arthritis biologics trials. J Rheumatol 2016:43:1024-6.

21 Goodacre LJ, Goodacre JA. Factors influencing the beliefs of patients with rheumatoid arthritis regarding disease-modifying medication. Rheumatology 2004;43:583-6.

22 De Rycke L, Maas M, Tak PP, et al. 'MRI-tis' in the early diagnosis of axial SpA: issues and limitations. Nat Rev Rheumato/ 2010;6:666-9.

23 Taurog JD, Chhabra A, Colbert RA, et al. Ankylosing spondylitis and axial spondyloarthritis. N Eng/ J Med 2016:374:2563-74.

24 Christiansen AA, Hendricks O, Kuettel D, et al. Limited reliability of radiographic assessment of sacroiliac joints in patients with suspected early spondyloarthritis. J Rheumatol 2017:44:70-7.

25 Turina MC, Yeremenko N, van Gaalen F, et al. Serum inflammatory biomarkers fail to identify early axial spondyloarthritis: results from the SpondyloArthritis caught early (SPACE) cohort. RMD Open 2017;3:e000319.

26 Rudwaleit M, Metter A, Listing J, et al. Inflammatory back pain in ankylosing spondylitis: a reassessment of the clinical history for application as classification and diagnostic criteria. Arthritis Rheum 2006:54:569-78.

27 Sieper J, van der Heijde D. Review: nonradiographic axial spondyloarthritis: new definition of an old disease? Arthritis Rheum 2013;65:543-51.

28 Deodhar A, Strand V, Kay J, et al. The term 'nonradiographic axial spondyloarthritis' is much more important to classify than to diagnose patients with axial spondyloarthritis. Ann Rheum Dis 2016:75:791-4.

29 Brandt HC, Spiller I, Song IH, et al. Performance of referral recommendations in patients with chronic back pain and suspected axial spondyloarthritis. Ann Rheum Dis 2007;66:1479-84. 
30 Braun A, Saracbasi E, Grifka J, et al. Identifying patients with axial spondyloarthritis in primary care: how useful are items indicative of inflammatory back pain? Ann Rheum Dis 2011;70:1782-7.

31 Rudwaleit M, Sieper J. Referral strategies for early diagnosis of axial spondyloarthritis. Nat Rev Rheumatol 2012;8:262-8.

32 van Hoeven L, Luime J, Han $\mathrm{H}$, et al. Identifying axial spondyloarthritis in Dutch primary care patients, ages 20-45 years, with chronic low back pain. Arthritis Care Res 2014;66:446-53.

33 Wanders A, Heijde D, Landewé R, et al. Nonsteroidal antiinflammatory drugs reduce radiographic progression in patients with ankylosing spondylitis: a randomized clinical trial. Arthritis Rheum 2005;52:1756-65.

34 Kroon F, Landewé $\mathrm{R}$, Dougados $\mathrm{M}$, et al. Continuous NSAID use reverts the effects of inflammation on radiographic progression in patients with ankylosing spondylitis. Ann Rheum Dis 2012;71:1623-9.
35 Haroon N, Inman RD, Learch TJ, et al. The impact of tumor necrosis factor ? inhibitors on radiographic progression in ankylosing spondylitis. Arthritis Rheum 2013;65:2645-54.

36 Baraliakos X, Haibel H, Listing J, et al. Continuous long-term anti-TNF therapy does not lead to an increase in the rate of new bone formation over 8 years in patients with ankylosing spondylitis. Ann Rheum Dis 2014;73:710-5.

37 Sieper J, Listing J, Poddubnyy D, et al. Effect of continuous versus on-demand treatment of ankylosing spondylitis with diclofenac over 2 years on radiographic progression of the spine: results from a randomised multicentre trial (ENRADAS). Ann Rheum Dis 2016;75:1438-43.

38 Sieper J, Poddubnyy D. New evidence on the management of spondyloarthritis. Nat Rev Rheumatol 2016;12:282-95.

39 Guyatt GH, Oxman AD, Vist GE, et al; GRADE Working Group. GRADE: an emerging consensus on rating quality of evidence and strength of recommendations. Bmi 2008;336:924-6.

40 Graudal N, Hubeck-Graudal T, Faurschou M, et al. Combination therapy with and without tumor necrosis factor inhibitors in rheumatoid arthritis: a Meta-Analysis of randomized trials. Arthritis Care Res 2015;67:1487-95.

41 Araújo FC, Gonçalves J, Fonseca JE.

Pharmacoeconomics of biosimilars: what is there to gain from them? Curr Rheumatol Rep 2016;18:50.

42 Dörner T, Strand V, Cornes P, et al. The changing landscape of biosimilars in rheumatology. Ann Rheum Dis 2016;75:974-82.

43 Lukas C, Landewé R, Sieper J, et al; Assessment of SpondyloArthritis international Society. Development of an ASAS-endorsed disease activity score (ASDAS) in patients with ankylosing spondylitis. Ann Rheum Dis 2009;68:18-24. 